\title{
VISÕES DO INFERNO \\ A sociabilidade do "homem comum" brasileiro em Florestan \\ Fernandes e Maria Sylvia de Carvalho Franco
}

\section{VISIONS FROM HELL The sociability of the Brazilian "common man" in Florestan Fernandes and Maria Sylvia de Carvalho Franco}

\author{
Marcos Marques de Oliveira \\ Universidade Federal Fluminense, Faculdade de Educação, Programa de Pós-Graduação em Educação. Campus \\ do Gragoatá, Bloco D - Rua Professor Marcos Valdemar Freitas Reis, s/n, São Domingos, Niterói - RJ, Brasil, \\ CEP 24210-201. \\ E-mail:marcos_marques@id.uff.br | ORCID: https://orcid.org/0000-0002-7451-558X
}

\begin{abstract}
Resumo: Este estudo debruça-se sobre duas das mais importantes obras da chamada Escola Paulista deSociologia, promotora de um elenco de indagações teóricas e investigações empíricas fundamentais na ciência social brasileira. Uma escola que se caracterizou pela constituição de uma sociologia enraizada nas singularidades históricas, sociais e culturais brasileiras, buscando o entendimento das condições específicas desta sociedade internamente marcada por ritmos desiguais de desenvolvimento, enfatizando a necessidade de uma compreensão mais efetiva, densa e profunda de seus diversos agentes - com destaque dos contingentes populacionais que mais sofreram com os nossos históricos processos de socialização e conformação ao modo de produção capitalista, ainda hoje hegemônico. Para cumprir este objetivo é que selecionamos, para uma análise sócio-histórica comparativa, as seguintes contribuições: A integração do negro na sociedade de classes, de Florestan Fernandes (2008a; 2008b); e Homens livres na ordem escravocrata, de Maria Sylvia de Carvalho Franco (1997).
\end{abstract}

Palavras-chave: pensamento social brasileiro, Escola Paulista de Sociologia, Florestan Fernandes, Maria Sylvia de Carvalho Franco.

Abstract: This study focuses on two of the most relevant works of the so-called Paulista School of Sociology which has been responsible for critical theoretical and empirical work in Brazil. This school of thought has proposed that the constitution of Brazilian sociology is rooted in historical, social and cultural singularities of Brazil, internally characterized by uneven development rhythms that require a more effective, dense and profound understanding of its various agents. Accordingly, the Paulista School of Sociology focuses on population contingents that suffered the most from Brazil's historical processes of socialization and conformity to the capitalist mode of production, which remains hegemonic today. The present work carries out a comparative socio-historical analysis of the following contributions: A integração do negro na sociedade de classes, by Florestan Fernandes (2008a; 2008b); and Homens livres na ordem escravocrata, by Maria Sylvia de Carvalho Franco (1997).

Keywords: brazilian social thought, Paulista School of Sociology, Florestan Fernandes, Maria Sylvia de Carvalho Franco. 


\section{Introdução}

Em 1959, chegava a público uma das mais importantes obras do historiador Sérgio Buarque de Holanda (2000): Visão do Paraíso. Os motivos edênicos no descobrimento e colonização do Brasil. Na verdade, uma versão remoçada de uma tese defendida no ano anterior, para a cátedra de História da Civilização Brasileira, na Universidade de São Paulo (USP). No prefácio a uma segunda edição, escrito em 1968, Holanda reforça que não foi seu intuito "mostrar o processo de elaboração, ao longo dos séculos, de um mito", mas apenas situá-lo historicamente, "na medida em que, com o descobrimento da América, pareceu ele [o mito] ganhar mais corpo até ir projetar-se no ritmo da História" (Holanda, 2000, p. IX). Com "ambições menos especulativas", o que o autor objetivava demonstrar era:

Até onde, em torno da imagem do Éden, tal como se achou difunda na era dos descobrimentos marítimos, se podem organizar num esquema altamente fecundo muitos dos fatores que presidiram a ocupação pelo europeu do Novo Mundo, mas em particular da América Hispânica, e ainda assim enquanto abrangessem e de certa forma explicassem o nosso passado brasileiro. (Holanda, 2000, p. X)

Neste sentido, ele lembra que a noção teológica de "Paraíso Terreal”, desde a Idade Média, não se assentava na representação de "um mundo intangível, incorpóreo, perdido no começo dos tempos" (Holanda, 2000, p. X). Mais do que uma fantasia piedosa, se vislumbrava uma realidade presente, ainda que em um "sítio recôndito, mas porventura acessível". Era algo que habitava a imaginação de navegadores, exploradores e povoadores deste "novo" hemisfério ocidental, tal como se prenunciou nas primeiras narrativas de viagens e nos primeiros tratados descritivos nos quais as visões de Paraíso contrastavam, paradigmaticamente, com "o antigo cenário familiar" dos europeus. Um cenário de "paisagens decrépitas" e de "homens afanosos", que se debatiam contra uma pobreza áspera, num Velho Mundo em que a natureza regateava, de forma avara, suas dádivas - trazendo benefício apenas aos ditos previdentes, aos diligentes e aos pacientes.

No "paraíso americano", o mundo natural parecia estar em plenitude. "Como nos primeiros dias da Criação, tudo aqui era dom de Deus, não era obra do arador, do ceifador ou do moleiro" (Holanda, 2000, P. XI). Um sinal de perfeição, já que não era preciso apelar, para sobreviver, ao duro trabalho dos homens. Imagem canônica de justificativa da cobiça e do banimento do labor, que pode ser exemplificada por este trecho de História da América Portuguesa, de Rocha Pita, de 1730, o primeiro livro de História do Brasil escrito por um "brasileiro", (citado em Carvalho, 1998, p. 3): 
Em nenhuma outra região se mostra o céu mais sereno, nem madruga mais bela a aurora; o sol em nenhum outro hemisfério tem raios tão dourados, nem os reflexos noturnos tão brilhantes; as estrelas são mais benignas e se mostram sempre alegres; os horizontes, ou nasça o sol, ou se sepulte, estão sempre claros; as águas, ou se tomem nas fontes pelos campos, ou dentro das povoações nos aquedutos, são as mais puras; é enfim o Brasil Terreal Paraíso descoberto, onde tem nascimento e curso os maiores rios; domina salutífero clima; influem benignos astros e respiram auras suavíssimas, que o fazem fértil e povoado de inumeráveis habitadores.

É claro, alerta Carvalho (1998), que o elogio deste novo "jardim do mundo" tinha mais o tom de propaganda para atração de imigrantes a serem seduzidos por um projeto de colonização do que, realmente, a ingênua concretização da descoberta utópica de um paraíso terreno. Fundia-se a imagem corpórea desse "espanto de natureza", no qual se conjugavam as belezas naturais, a fertilidade do solo e as riquezas minerais de uma "completa primavera", com a ideia que se mostrará perversa - tanto no norte, quanto no sul - de uma "América sem alma", que haveria de se converter numa outra espécie de paraíso.

Não por acaso, é que, ao lado da persistência do motivo edênico na história de constituição das instituições brasileiras, desenvolve-se o que Carvalho identificou como "a razão satânica", que ele bem define com a seguinte epígrafe retirada de uma obra de Paulo Prado (1928, citado em Carvalho, 1998, p. 10): “Numa terra radiosa, vive um povo triste". Para essa "razão satânica", tão imaginária quanto à visão edênica, o que caracterizaria este novo mundo seria, justamente, a existência de um "elemento humano" inadequado, seja o homem nativo ou o imigrado pioneiro, que vão sempre parecer estar aquém das qualidades da terra e do clima. Uma versão aguda desta "razão satânica" ganhará máscaras cientificistas a partir do século XIX, quando teorias racistas, de diferentes graus e características, farão grande sucesso entre diversas correntes intelectuais, tais como na proto-sociologia de Sílvio Romero, na literatura jornalística de Euclides da Cunha e, entre outros, na antropologia eugenista de Nina Rodrigues. Numa terra em que "tudo é grande, só o homem nada vale" - frase atribuída a Sílvio Romero (Carvalho, 1998, p. 11) - a visão do poeta irlandês Thomas Moore, que esteve na América no início do século XIX, de que aqui "à grandiosidade da natureza correspondia uma população selvagem, fraca, repugnante, idiota", parecia confirmada.

Mas este costuma ser o equívoco dos que se restringem ao impressionismo de uma "história das mentalidades" tomada, afirma Buarque, apenas no sentido de uma "história das idéias conscientemente adotadas" (Holanda, 2000, p. XVII), que acaba por redundar em visões distópicas de um suposto "espírito nacional" trancafiado numa "imutável característica étnica" (Holanda, 2000, p. XIX), da qual 
indivíduos e coletividades de uma determinada sociedade estariam irremediavelmente presos, seja no tempo ou no espaço. Como é o caso das tentativas, não desinteressadas, dos que passaram a defender o "envelhecimento precoce" da nuestra América, tida como um mundo já gasto e degenerado - ou quando não dos que defenderam sua imagem contrária, mas equivalente, "de um mundo inacabado ou imaturo" (Holanda, 2000, p. XXVI). Nos dois casos, contrariando a lição hegeliana de "que é impróprio ao mister de filósofo o pretender ser profeta" (Holanda, 2000, p. XXVI). Para evitar essa "taumaturgia", Buarque propõe que o historiador funcione como um "exorcista", buscando "afugentar do presente os demônios da História" (Holanda, 2000, p. XXVI).

Não se questiona a validade social da investigação histórica. Menos ainda que não se deva levar a sério o estudo das ideias e dos intelectuais, já que estas, dependendo de suas qualidades e pertinências, podem assumir grande importância nos próprios processos sociais que investigam - tal como veremos a seguir, com o exemplo do questionamento que Florestan Fernandes faz do mito da "democracia racial brasileira". O que se salienta é o limite deste tipo de exercício quando toda e qualquer "história das mentalidades" se restringe a uma reles observação da história das elites, especialmente as ditas "pensantes". Tal como sugere Monsma (2016), quando vai investigar as contradições e permanências entre as ideologias racistas das elites e o que chama de habitus racial popular no período pós-abolição brasileiro:

Esta ênfase na vida cotidiana difere do que predomina nos estudos brasileiros do racismo, que geralmente focalizam as ideologias raciais produzidas por intelectuais urbanos, com ênfase central na recepção brasileira do racismo científico europeu. Sem dúvida as elites locais e os imigrantes, inclusive os analfabetos, eram expostos, em algum grau, às ideologias raciais dos intelectuais, mas presumir que eles simplesmente adotavam essas ideologias é exagerar a influência dos intelectuais. (Monsma, 2016, p. 18-19)

Na hipótese que atravessa este estudo, esta "estratégia de análise" é, justamente, uma das mais importantes contribuições da Escola Paulista de Sociologia, promotora de um elenco de indagações teóricas e investigações empíricas fundamentais na ciência social brasileira. Uma escola que, segundo Martins (1998, p. 18), nela formado, se caracterizou pela constituição de uma sociologia enraizada nas singularidades históricas, sociais e culturais brasileiras, buscando o entendimento das condições específicas desta sociedade internamente marcada por ritmos desiguais de desenvolvimento, enfatizando a necessidade de uma compreensão mais efetiva de seus diversos agentes - com destaque, ainda que não exclusivo, dos contingentes 
populacionais que mais sofreram com os históricos processos de socialização e conformação ao modo de produção capitalista, ainda hoje hegemônico.

Para cumprir este objetivo é que selecionamos, para uma análise sócio-histórica comparativa sintética, dois de seus estudos. Começamos com A integração do negro na sociedade de classes (Fernandes, 2008a; 2008b), obra com a qual Florestan, o fundador dessa escola, se torna catedrático da USP, em 1965, promovendo a desconstrução do mito da democracia racial brasileira e combatendo as explicações culturalistas sobre a formação do "caráter" nacional. Demonstrando, com ela, que a dita "não-integração" do negro na nossa sociedade de classes devia-se, entre outros fatores, à pauperização decorrente das dificuldades de sua inclusão no mercado de trabalho livre em formação, o que permitiu a continuidade das indignas condições de vida herdadas do regime escravagista.

A seguir, abordaremos os aspectos principais de outro clássico: Homens livres na ordem escravocrata, de autoria de Maria Sylvia de Carvalho Franco (1997). Publicada em 1969, mas produto de sua tese doutoral em Ciências Sociais na USP, defendida em 1964, orientada por Florestan, a obra em foco dá um tratamento "heterodoxo" ao fenômeno do convívio entre o "atrasado" e o "moderno" no processo de formação da sociedade brasileira, afastando-se tanto dos "teóricos do subdesenvolvimento" (Piozzi, 1997) quanto dos da "modernização" (Botelho, 2013), que tanto sucesso faziam à época.

Sua resposta à hipótese que nos ajudar a entender melhor os motivos que levaram os homens pobres livres, os que não eram, portanto, nem senhores e nem escravos (Kowarick, 2019), a não assumir o lugar destes últimos nas lavouras de café do Vale do Paraíba, passa pela demonstração de como a "dominação pessoal", que predominou no Estado e nas práticas de mercado, foi um princípio geral de coordenação das relações sociais no Brasil - mas sem caracterizar ou qualificar, como afirma Botelho (2013, p. 331), "esse tipo de associação moral que ligava homens livres pobres e fazendeiros como marca de uma sociedade tradicional, ou atrasada, ou ainda incompatível com os processos de mudança social e o dinamismo que o capitalismo ia assumindo também entre nós".

Essas duas obras não resumem a vasta contribuição da Escola Paulista de Sociologia. Mas, para a consecução dos nossos objetivos, as interpretações que fazem, respectivamente, das condições de vida dos escravos e dos homens pobres livres em conjunto com os imigrantes pobres europeus, outro contingente populacional que será foco de análise de outras obras desta mesma escola - fornecem pistas para entendermos a constituição da sociabilidade do "homem comum" brasileiro, que se caracteriza, especialmente, por sua persistente capacidade de postergação da ascensão social coletiva - geratriz, segundo Martins (2018, p. 10), de uma 
sociedade que permanece conformista e despolitizada, justamente porque tem a capacidade de reconstituir, permanentemente, formas novas e indignas de relações de trabalho congêneres.

\section{A (des)integração do negro brasileiro}

As preocupações de Florestan sobre as chamadas "questões étnico-raciais" se inauguram com seus estudos sobre o folclore paulistano, ainda quando aluno de Ciências Sociais da USP, no final dos anos 1940. Um tema afinado com sua história de menino oriundo do lumpesinato, naquela que se tornaria a mais importante metrópole brasileira: a cidade de São Paulo. Em suma, os estudos do jovem pesquisador sobre as trocinhas, provérbios, jogos de salão, cantigas de piquenique, superstições, ditos e frases feitas, rodas, parlendas e pegas infantis dos desenraizados paulistanos são prova de sua "projeção endopática" com aquela forma de infância que, de alguma maneira, era a sua própria (Fernandes, 2003, p. XXI).

No conjunto desses estudos, é que se encontram seus escritos pioneiros sobre o que futuramente ele vai denominar de "dilema racial brasileiro". Dessa primeira leva, destacam-se três artigos sobre o negro na tradição oral, que ele publica pelas páginas do Estado de S. Paulo, e, ainda, a produção de biografias de pais de santo negros, tal como a que fez sobre João de Camargo, fundador, em Sorocaba, interior de São Paulo, da Igreja Nosso Senhor do Bom Jesus da Água Vermelha. Esses estudos sobre o sincretismo religioso foram encomendados pelo professor Roger Bastide, sociólogo e antropólogo francês com o qual Florestan irá compartilhar, a seguir, num trabalho para a Organização das Nações Unidas para a Educação, a Ciência e a Cultura (UNESCO), o desafio de compreender a dinâmica do que se acreditava ser os fundamentos da "democracia racial brasileira".

O Projeto UNESCO, como ficou conhecido, foi um conjunto de pesquisas realizado no início dos anos 1950, em algumas regiões do país, com o intuito de apresentar ao mundo uma experiência de interação racial tida, naquele momento, como bem-sucedida. Tal projeto toma forma quando o antropólogo Alfred Métraux assume o recém-criado Setor de Relações Raciais do Departamento de Ciências Sociais do respectivo organismo multilateral, escolhendo Ruy Coelho, outro uspiano, para coordenador geral da iniciativa. É este que, por sua vez, convida Bastide para dirigir a pesquisa em São Paulo. Florestan, orientando de Bastide, resiste inicialmente devido ao seu interesse em terminar os estudos de pós-graduação. Mas, comovido pelo pedido do mestre, e tocado pelas suas vivências no subúrbio paulistano, onde teve contato com "as condições reais de vida do negro entre nós" (Fernandes, 1995, citado em Maio, 1997, p. 176), acaba se envolvendo. Os primeiros 
resultados são apresentados no texto Relações Raciais entre Brancos e Negros em São Paulo, em 1955. Mais tarde o trabalho seria republicado com o título Brancos e Negros em São Paulo: ensaio sociológico sobre aspectos da formação, manifestações atuais e efeitos do preconceito de cor na sociedade paulistana (Fernandes \& Bastide, 1971).

O primeiro impacto causado pela obra foi o conjunto de inovações metodológicas criadas por Florestan para realizar a pesquisa, começando, salienta Heloísa Martins (2004, p. 292), o fato de ter, "pela primeira vez" na USP, levado os pesquisados para o interior da respectiva instituição. Os debates com líderes e representantes dos movimentos negros de São Paulo foram realizados em três níveis: um grupo maior se reunia mensalmente; outro, constituído de mulheres negras, quinzenalmente; e, por fim, um grupo específico de intelectuais negros mantinha encontros semanais com os pesquisadores ${ }^{1}$.

De acordo com Florestan (1989, citado em Soares et al., 2002, p. 38), "o alvo cognitivo maior não era reproduzir as situações grupais como ‘situações de laboratório'. Ele consistia em reproduzir o concreto a partir das experiências humanas observadas", dando ênfase, portanto, aos aspectos mais densos da vida cotidiana - tal como sugere Monsma (2016) para estudos deste tipo. A explicação desta realidade histórica se complementava com "uma abordagem interdisciplinar que tinha como premissa a fusão das dimensões micro e macro da economia, da personalidade, da cultura e da sociedade" (Fernandes, 1989, citado em Soares et al., 2002, p. 38). Questionários, entrevistas ocasionais, entrevistas formais, biografias e histórias de vida foram as técnicas de pesquisa utilizadas para se ter acesso às manifestações raciais da população - incluindo, além dos grupos negros citados, gente da população branca, de famílias tradicionais e imigrantes, e dos setores industrial, serviços e comércio. Esse arsenal metodológico possibilitou a análise da desagregação da sociedade escravagista e a formação da sociedade de classes, tendo em vista as contradições presentes na organização social e cultural, "evidenciando-se de que maneira a assimetria presente nas relações raciais do passado foi reabsorvida e redefinida 'sob a égide do trabalho livre e das novas condições histórico-sociais'” (Soares et al., 2002, p. 38).

Pelos primeiros resultados, as pesquisas de Bastide e Florestan foram tomadas como uma tentativa de "introdução" do problema racial no Brasil - como se a culpa fosse dos pesquisadores, não da situação específica analisada. Em suma, o Projeto UNESCO, ao invés de encontrar soluções para os problemas raciais, acabou por identificar uma forma bem específica de preconceito e discriminação. O Brasil,

Sobre o tema, conferir o estudo de Campos (2014), que destaca as estratégias de interação metodológica entre Florestan Fernandes e os intelectuais e membros dos círculos sociais negros de São Paulo. 
como "laboratório", apresentou situação oposta à idílica idéia de que o seu modelo de escravidão teria sido "mais humano" do que outros. E, mais importante que isso, suas conseqüências estavam longe de confirmar o mito da democracia racial que havia sido propagado por estudos anteriores, especialmente os do sociólogo Gilberto Freyre (Bastos, 1987).

O Projeto UNESCO teve outros desdobramentos, dada a participação de diversos importantes pesquisadores, tal como a de Oracy Nogueira (2006), criador da distinção entre o preconceito de marca, existente no Brasil, e o preconceito de origem, vigente nos Estados Unidos. Mas, no caso específico de Florestan, o ponto culminante será o aproveitamento dos dados colhidos para a elaboração da tese - $A$ integração do negro na sociedade de classes - com a qual ele se torna professor titular da universidade que lhe formou. Nesse documento, fica mais explícita a sua recusa da perspectiva conservadora sobre a questão racial no Brasil, mesmo se considerarmos que seu foco de análise é São Paulo, o maior centro urbano tipicamente burguês do país. Nesse espaço atravessado por relações sociais modernas, o negro livre, em sua maioria, acabou por se apegar a condições sociais de existência não tipicamente capitalistas - sofrendo, assim, o drama de sua "desintegração" à sociedade de classes nascente, devido à ausência de um processo de ressocialização para enfrentar a nova ordem estabelecida.

A mutação de uma cidade de matriz rural (com a prevalência do sentido comunitário, coletivo e tradicional) para uma de matriz urbana (individualista e com base na ordem social competitiva) tornou a condição de vida dos antigos escravos e descendentes ainda mais adversa - o que acabou por se agravar com a política oficial de apoio à imigração estrangeira. Sem essa ressocialização, a ordem inclusiva é resistida a partir de elementos morais, acarretando na descrença do sistema contratual e proporcionando uma percepção do trabalho sob critérios ainda não-capitalistas - o que faz com que o maior contingente de negros fique à margem da estrutura sócio-econômica em ebulição. A ordem social competitiva acaba sendo invadida por formas de vida e hábitos patrimonialistas, o que torna a democratização das relações sociais lenta e rarefeita, especialmente pela concentração dos instrumentos de ascensão social nas classes dominantes. As táticas de luta dos ex-escravos, nessas condições, passam por tentativas de definição de um espaço social que parece à margem da sociedade inclusiva. Vive-se um círculo vicioso em que as suas novas atividades se restringem a atividades similares ao do antigo regime - sem contar com o abrigo dos velhos costumes, dada a crise de sua herança cultural.

O meio negro, sozinho e isolado, reforça e recria fórmulas de ajustamento com raízes passadistas, promovendo o bloqueio de sua ressocialização pela falta 
de modernização do estoque de idéias, comportamentos e valores nas áreas mais vitais e dinâmicas do processo de urbanização. Enquanto isso, os brancos alargam a distância em relação aos novamente excluídos.

O negro muda em função de uma história que não é a dele, mas a do branco. O homem de cor é, de modo geral, um homem dividido, dilacerado. Socializado no seio da cultura dominante do branco, ele aprende desde pequeno a internalizar os modelos, os valores, os ideais dos brancos. Sofre um processo de embranquecimento psíquico compulsório: "existe nele um brancor"; "ele deveria ser uma coisa, e ele é outra". (Lépine, 1987, p. 134)

A prova, afirma Bastos (1987, p. 148), de que o mito da democracia racial é uma formulação equivocada e hipócrita, baseada na ilusão de que a ordem social competitiva, em solo tupiniquim, está aberta a todos - forjando a crença de que há um paralelismo "entre a estrutura social e a estrutura racial da sociedade brasileira".

Não se trata de uma formulação sem sentido. Serve a uma constelação de interesses, entre os quais isentar as elites de culpas e evitar a realização efetiva da integração racial democrática. É a forma pela qual as elites exorcizam a ameaça dos movimentos sociais. (Bastos, 1987, p. 148)

A limitação que Florestan vê nos movimentos sociais negros não significa que ele tenha sido "pouco sensível" à presença política das massas. Segundo Arruda (1996, p. 199), o sociólogo reconhece que "o protesto negro, muito embora não fosse suficientemente forte para superar as desigualdades raciais", representava potencialmente "a construção de uma nova era histórica na qual os herdeiros do cativeiro começam a afirmar-se como homens livres e cidadãos".

Monsma (2016, p. 24) registra que muitos analistas discordam da "afirmação" de Florestan de que a escravidão, para além do legado racista, deixou entre os negros traços de anomia, indisciplina e irresponsabilidade que acarretaram na incapacidade de competir com os imigrantes no mercado de trabalho "livre" em formação, assim como uma baixa capacidade de resistência ou rebelião ao conjunto das situações de opressão e, por fim, com poucas condições de estipular boas negociações coletivas de superação das situações indignas de existência humanitária. Ora, levando em conta que Florestan, como exímio sociólogo, descartava toda e qualquer explicação "genética" ou racial para tais desvantagens, o próprio Monsma (2016, p. 28-29) vai demonstrar que, justamente, foram três os fatores que possibilitaram a "persistência da dominação [e do habitus] racial" entre nós, se aproveitando do que ele chama, senão de "anomia", mas de "certas vulnerabilidades da população negra", se comparadas, por exemplo, com a situação dos imigrantes europeus: i) a inexistência de uma 
elite negra capaz de reverter os estereótipos negativos deste contingente; ii) a ausência de redes sociais densas que pudessem impulsionar ações institucionais (jornais, escolas e associações, etc.) direcionadas e em defesa de suas famílias e comunidades étnicas; iii) a constituição de representações e rotinas racializadas, configuradoras de um habitus racial de grande resistência à continuidade de relações de subordinação aos antigos senhores, algo plenamente compreensível frente à memória recente dos muitos anos de aviltamento - o que não acontecia com a leva de imigrantes europeus, que vinham, inclusive, bastante seduzidos com a ilusão de "fazer a América", prontos, em sua grande parte, para aceitar condições não tão dignas assim de trabalho e subsistência.

Do nosso ponto de vista, rejeitando a hipótese de que Florestan teria reforçado "de certa forma" o estereótipo do "negro vagabundo" (Monsma, 2016, p. 106), tais fatos apenas evidenciam que o sociólogo, apesar de sempre comprometido com algum tipo de programa socialista em termos políticos e sociais, não se permitiu, na sua pesquisa, uma leitura idealista sobre as possibilidades concretas dos que sofrem as conseqüências perversas de um determinado modo de produzir e viver. E, o mais importante, é que mesmo sob uma análise pessimista ele acabou por salientar o "poder que os grupos possuem, através da educação, da conscientização e da atuação política, de modificar a orientação da evolução das estruturas sociais e de dirigir o seu próprio destino" (Lépine, 1987, p. 137).

Enfim, se o inconformismo negro não teve como vencer, ele não pôde e nem pode dar como acabado. Para Florestan, lembra Gabriel Cohn (2000, p. 399), a validade de um movimento social não se mede pelo êxito em viabilizar os alvos perseguidos; mas pelo seu vigor combativo, especialmente quando capaz de oxigenar as condições concretas de opressão numa sociedade determinada.

Sob os olhos impassíveis, perplexos ou hostis dos "brancos", ergueu-se o "protesto negro", como o "clarim da alvorada", inscrevendo nos fatos históricos da cidade [de São Paulo] os pródromos da Segunda Abolição. [...] Arrogando-se a solução de problemas ignorados ou descurados pelas elites no poder, o negro e o mulato chamaram a si duas tarefas históricas: de desencadear no Brasil a modernização do sistema de relações sociais; e de provar, praticamente, que os homens precisam se identificar, de maneira íntegra e consciente, com os valores que encarnam a ordem legal escolhida. (Fernandes, 2008b, pp. 09-10)

Finalizamos esta reflexão afirmando que a questão étnico-racial na obra de Florestan, ainda que sob o enfoque não explicitamente materialista e dialético, não estava descolada da questão classista - já que aquela, no caso brasileiro, segundo o sociólogo, é a base fulcral da negação da "questão social" pela burguesia ascendente. 
Esta, para impor seu projeto político, deita suas raízes em alianças com os setores tradicionais, bebendo de seus valores, de suas práticas e de suas idéias - garantindo uma forma de encaminhamento "pelo alto" da transição "modernizadora" que aqui se desenrola. Neste sentido, podemos dizer que os estudos de Florestan sobre o dilema racial brasileiro integram um conjunto de reflexões sobre os limites da ordem social competitiva instalada no país, que logo a seguir vão culminar na sua obra seminal: A revolução burguesa no Brasil: ensaio de interpretação sociológica (Fernandes, 1975).

Vale lembrar, ainda, que os estudos iniciados com o Projeto UNESCO, consolidados com a publicação de $A$ integração do negro na sociedade de classes, fez com que Florestan despontasse como um eminente intelectual público, aproveitando essa experiência para impulsionar o seu trabalho junto à cadeira de Sociologia I na USP, estimulando o surgimento e a consolidação da chamada Escola Paulista de Sociologia, da qual saíram intelectuais de renome das ciências sociais brasileira, tais como Fernando Henrique Cardoso e Octavio Ianni. Estes, inclusive, com obras marcantes no campo das investigações sobre as relações étnico-raciais (Cardoso, 1977; Ianni, 2004). E é integrado a este cenário intelectual que desponta a pesquisa de Carvalho Franco, trazendo novos elementos reflexivos para o entendimento das relações sociais matriciais brasileiras ${ }^{2}$.

\section{Para além da casa-grande e senzala}

O escravo aparecerá tratado, no decorrer deste livro, apenas de maneira circunstancial. Entretanto, ele existiu como "presença ausente", mas constante e pesada, no mundo dos homens livres que procurarei reconstituir. A ele esteve ligado não só o destino de seus proprietários, como também toda a sorte de homens livres e pobres, o que me obriga a pelo menos propor um ponto de vista sobre o lugar e o significado da escravidão na sociedade colonial. (Franco, 1997, p. 9)

Desta forma, quase que pedindo desculpas, é que Franco (1997) inicia a apresentação de sua pesquisa sobre Homens livres na ordem escravocrata - originalmente denominada Homens livres na velha civilização do café, tese de doutoramento em Ciências Sociais pela USP, defendida em 1964, com banca formada pelo orientador Florestan Fernandes, além dos pesquisadores Antonio Candido, Sérgio Buarque

Ressalta-se que esse processo de surgimento, conformação e consolidação da chamada Escola Paulista de Sociologia não se deu de forma contínua, sem disputas e rupturas. Além de sua gênese ter sido marcada pela própria busca da USP em se diferenciar de outras escolas sociológicas que se institucionalizavam no Brasil, o ambiente interno também foi marcado por divergências interpretativas sobre o processo de formação social do país. Sobre estas questões, conferir Pulici (2008). 
de Holanda, Octavio Ianni e Francisco Iglesias. Segundo Arruda (1994), a obra de Maria Sylvia está integrada a uma vertente de investigação que, a partir da década de 1950, se inaugura na USP: os estudos sobre relações raciais, a partir do projeto, já citado, de Roger Bastide e Florestan Fernandes.

\begin{abstract}
A tendência fundamental da análise reside na inserção do preconceito e das relações desencadeadas pelo fenômeno na estrutura social. Os autores orientam as suas reflexões, no interior da consideração de situações sociais propícias à emergência do preconceito. Em torno do tema do negro, Florestan Fernandes dirige pesquisas importantes, voltadas ao estudo das relações raciais, na gênese e desenvolvimento da sociedade brasileira. (Arruda, 1994, p. 319)
\end{abstract}

Nesse campo, além da obra de Franco, estão: o doutoramento de Fernando Henrique Cardoso (Formação e desintegração da sociedade de castas: o negro na ordem escravocrata do Rio Grande do Sul), em 1961; e o de Octavio Ianni (O negro na sociedade de classes), no mesmo ano. Spirandelli (2008, p. 159) afirma, entretanto, que a obra em questão marca a ruptura da aluna com o orientador, apontando como principal motivo as divergências de interpretação quanto ao significado da escravidão no Brasil: com a primeira tomando o fenômeno pela sua dimensão sociológica dentro de uma "formação social" complexa; e o segundo como um "modo de produção" específico que teria estruturado, per si, a sociedade brasileira. Ou seja, não desconsiderando a importância da escravidão como fato sociológico explicativo do processo histórico de formação do país; mas o tomando como fenômeno subordinado, ainda que peculiar, ao fenômeno de integração do Brasil à sociedade de classes internacional em formação.

Botelho (2013) corrobora a hipótese, afirmando que a "sociologia política" de Franco pode, sim, ser tomada como uma forte crítica às premissas dos trabalhos desenvolvidos na cadeira de Sociologia I, sob a responsabilidade de Florestan Fernandes. Para o fundador e parte dos seguidores da Escola Paulista, "a escravidão constituiria uma instituição essencial que articularia a totalidade da sociedade brasileira", o que faz com que a questão racial se torne "o objeto privilegiado para a compreensão das condições históricas e sociais de formação do povo" brasileiro. Já para a rebelde discípula, "a escravidão seria antes parte de um sistema socioeconômico mais amplo", obrigando, portanto, que a ênfase analítica recaia sobre as formas sociais assumidas pela grande propriedade fundiária no Brasil, com seu caráter autárquico, somado ao fato de existirem dentro de si imensas áreas ociosas e, por fim, sua ligação com a produção agrário-exportadora (Botelho, 2013, p. 338).

Não que Franco minimizasse a importância da escravidão, nem mesmo para a configuração da população "livre", que era o seu objeto. Mas ao enfatizar a "questão 
fundiária", a autora afirmava que a história da formação da sociabilidade brasileira passava pela compreensão da presença simultânea, no interior dos latifúndios, da produção da monocultura escravista para o exterior, da produção de subsistência e, ainda, da própria produção para o mercado interno - que seriam, enfim, "práticas constitutivas" simultâneas e recíprocas (Botelho, 2013, p. 339).

Segundo Franco (2011, p. 170), foi após uma frustrada "pesquisa de campo", sobre uma determinada comunidade do interior de São Paulo, que ela percebeu que as "chamadas relações comunitárias, de parentesco, de vizinhança ou de trabalho" tinham pouca validade - teórica e empírica - para uma efetiva "reconstituição histórica da vida caipira".

Nos arquivos, nova surpresa: a violência que os esquemas acadêmicos atribuíam essencialmente à escravidão [...] revelava-se enraizada em outro solo, mais compreensivo, permeando a sociedade como um todo, inclusive as "harmoniosas" comunidades. Pouco a pouco o quadro foi tomando forma e o recurso ao regime escravista [...] foi se determinando no interior do sistema capitalista, não como elemento justaposto pela atividade mercantil, mas como recurso rápido e plástico para suprir as necessidades de organização do trabalho postas pelas novas articulantes da produção e da circulação de mercadorias. (Franco, 2011, p. 170)

Ficou configurado, assim, o interesse da autora pelo mundo rural, com a sua disposição para enfrentar "os complicados problemas da estrutura agrária" na história brasileira, com vistas a elucidar as condições sociais que presidiram à constituição do "trabalhador rural" como tipo humano, expondo as pressões que tornariam difícil sua integração na sociedade como um sujeito autônomo. Vem daí a sua percepção e definição de "homens livres e expropriados", não integrados à produção mercantil, mas a ela articulada.

A constituição desse tipo humano prende-se à forma como se organizou a ocupação do solo, concedido em grandes extensões e visando culturas onerosas. Dada a amplitude das áreas apropriadas e os limites impostos à sua exploração pelo próprio custo das plantações, decorreu uma grande ociosidade das áreas incorporadas aos patrimônios privados, podendo, sem prejuízo econômico, ser cedidas para uso de outro. Esta situação - a propriedade de grandes extensões ocupadas parcialmente pela agricultura mercantil realizada por escravos - possibilitou e consolidou a existência de homens destituídos da propriedade dos meios de produção, mas não de sua posse [...]. Assim, numa sociedade em que há concentração dos meios de produção, onde vagarosa, mas progressivamente, aumentam os mercados, paralelamente forma-se um conjunto de homens livres e expropriados que não conheceram os rigores do trabalho forçado e não se proletarizaram. (Franco, 1997, p. 14) 
Formou se o que Franco (1997, p. 14) chamou de "ralé", um contingente de pessoas que vagou e cresceu durante quatro séculos por estas bandas: "homens a rigor dispensáveis, desvinculados dos processos essenciais à sociedade". Apesar disso, de estarem apartados da produção mercantil, "este setor localizou-os na estrutura social e definiu o seu destino" (Franco, 1997, p. 15). Eis, portanto, o sentido de nossa "modernidade", capitalista, sim, mas com acentuada peculiaridade nas suas singulares relações de dominação e de produção. Uma sociedade de "classes", mas com uma dinâmica particular - cuja definição do objeto e o plano do livro pretendiam desvendar.

Orecorte da pesquisa recai sobre o Vale do Paraíba, nas áreas de ebulição da produção cafeeira no século XIX, em territórios que abrangem dois dos mais importantes estados brasileiros: Rio de Janeiro e São Paulo. Centralizou-se, especificamente, na cidade de Guaratinguetá e adjacências, com vistas a apanhar "o momento em que atingia seu ponto alto a criatividade contida na organização agrária 'colonial'" (Franco, 1997, p. 17). Segundo Botelho (2013, p. 342), os homens livres e pobres de Franco "ganham inteligibilidade sociológica no âmbito da dominação marcada por relações diretas, pessoais e violentas, que formam uma rede de contraprestações de toda sorte de serviços prestados e favores recebidos". A autora demonstra que a violência própria das relações de dominação pessoal constitui, por complementaridade, as relações de solidariedade social internas dos grupos sociais analisados, colocando em cheque, inclusive, as próprias manifestações supostas de solidariedade social, tais como os "mutirões", tidos como uma forma "caipira" cooperativa de trabalho.

Segundo Franco (1997, p. 27), essa violência é cotidiana e atravessa "os setores menos regulamentados da vida, como as relações lúdicas, e projetando-se até a codificação dos valores fundamentais da cultura" - lembrando os aspectos "anômicos" que Florestan identificou na herança comportamental dos negros.

Deve-se considerar que o povoamento do interior fez-se pela disseminação de pequenos grupos esparsos em um amplo território e que a grande disponibilidade de terras férteis e a riqueza das fontes naturais de suprimento, aliadas à pobreza das técnicas de produção, definiram um modo de vida seminômade, baseado numa agricultura itinerante cujos produtos eram suplementados pela caça, pesca e coleta. Pode-se dizer que, ao longo de sua história, esses grupos só tiveram reforçada essa grande instabilidade. Até o presente, observa-se que a mobilidade lhes aparece como o único recurso contra condições adversas de existência: problemas com o patrão, salário baixo, trabalho insalubre, desavenças, desgostos resolvem-se ainda hoje com transferência de domicílio. (Franco, 1997, p. 31-32)

Como identifica Botelho (2013, p. 342), a análise de Franco "dá atenção especial ao sentido sociológico das componentes sociais intersubjetivas presentes nas relações 
de dominação política pessoalizadas", mas com profunda articulação com as condições de vida material e simbólica vividas por este contingente populacional. Um dos motivos para essa situação de "espantosa pobreza" cultural estaria nas formas que se organizaram a produção "colonial", que resultaram, para este grupo social, numa divisão do trabalho flexível, instável e insegura - que já não era compatível com uma solidariedade de tipo mecânica, tais como existentes nas sociedades ditas mais "simples", mas também com baixíssimo nível de organicidade interna, em curto prazo, e alta dependência das crises dos fluxos externos da economia mundial, em longo prazo.

Uma economia desse tipo, afirma Franco (1997, p. 33), baseada em tarefas simples e rotineiras, que são dominadas, potencialmente, por todos os membros do grupo, devido à necessidade de um mínimo de eficiência estabelecida socialmente, voltada, portanto, às condições básicas e imediatas de sobrevivência, "não sustenta formas de especialização e estratificação social", resultando num alto grau de mobilidade e numa estrutura social indiferenciada. Mas, como já dito, esta foi uma "marginalidade" constituída, eis o paradoxo da sociabilidade deste contingente de brasileiros, a partir da relação com um mundo que lhe era exterior. Basta lembrar, afirma Maria Sylvia (1997, p. 34), "que o soldado, o padre, a autoridade pública estiveram sempre referidos a instituições alheias ao mundo caipira".

Desse processo, um dos resultados foi o fortalecimento do estigma de "preguiçoso", já que para os olhares externos havia um grande "desperdício da força de trabalho" de um grupo que abrangia $2 / 3$ da população no início do século XIX. Já vimos que Franco não nega que essa condição de vida, voltada aos "mínimos vitais", como identificou Candido (2010), tinha ligações com um mundo que lhe era paralelo. Mas ressalva que a regularidade de aproveitamento dos chamados "homens pobres livres e sem posses" foi rarefeita, voltada a tarefas de grande risco aos fazendeiros (derrubada de florestas, criação de gado e, entre outras, funções de tropeiro e carreiro), e que não podiam, por motivos óbvios (possibilidade de fuga e rebelião), serem delegadas aos escravos.

Entre os efeitos dessa dinâmica de relações sociais, a autora vai apontar duas características marcantes da vida caipira: a "violência" como prática costumeira de resolução de conflitos entre os próprios, não sendo incomum mesmo "no curso de brincadeiras"; e, por complemento, a aceitação da "dominação pessoal", sustentada por relações de contraprestação entre eles, mas especialmente com os "de cima", devido a uma aparente situação de "indistinção social" corroborada pelo "estilo de vida" simples e rústico, decorrente de uma situação generalizada de penúria material naquela região. De um lado, portanto, o conflito violento tornando-se inerente à dinâmica da própria situação de trabalho e da vida cotidiana. De 
outro, a configuração e a perpetuação das relações de dependência com os estratos superiores, que aparentam mais como uma "inclinação de vontades" e "harmonia" do que como imposição "do mais forte sobre o mais fraco" - fazendo com que as tensões comuns nestas relações permaneçam ocultas, com raras "possibilidades de emergirem à consciência dos dominados" (Franco, 1997, p. 95).

Neste ponto, Maria Sylvia faz uma interessante observação sobre como "este tipo de dominação pode exterminar a vontade do homem a ele submetido e reduzi-lo à inércia", sendo um tipo de condição alienada, potencial e simbolicamente, mais profunda do que a própria escravidão.

Na propriedade servil, embora o escravo seja transformado em coisa e a extinção de sua consciência vá ao limite da autonegação como pessoa, existem marcas violentas que denunciam a opressão que sobre ele pesa e na medida possibilitam pelo menos um "vago desejo de liberdade", "uma mera necessidade subjetiva de afirmação que não encontra condições de realizar-se concretamente". Liberdade impossível mas pelo menos desejada, o que devolve ao escravo, embora apenas como projeção individual, um sentido de humanidade. Para aquele que se encontra submetido ao domínio pessoal, inexistem marcas objetivadas do sistema de constrições a que sua existência está confinada: seu mundo é formalmente livre. Não é possível a descoberta de que sua vontade está presa à do superior, pois o processo de sujeição tem lugar como se fosse natural e espontâneo. (Franco, 1997, p. 95)

Diminuem-se as possibilidades de autoconsciência, já que estão dissolvidas na vida social as referências da quais ela poderia se constituir. Um exemplo dessa dissolução acontece nas relações de parentesco entre os homens livres pobres, fenômeno que se contrapõe, mas também se articula, com "o padrão de organização da família tradicional brasileira", vigente nas camadas mais altas da sociedade, até o final do século XIX. Nesse período, este padrão, de caráter "patriarcal", apresentou uma estrutura dupla: "um núcleo legal, composto do casal e seus filhos legítimos, e a periferia, constituída por toda sorte de servidores e dependentes" (Franco, 1997, p. 44).Não vigia, nessas relações, uma identidade efetivamente afetiva, mas sim vínculos definidos por situações de interesse, com vistas à preservação e ao equilíbrio familiar no núcleo central, que visavam, por complemento, à unificação dos controles sociais cuja legitimidade se baseava na dupla face da sociedade brasileira em formação: "o lar e a empresa, amálgama de que se fez a grande propriedade fundiária" (Franco, 1997, p. 45), a alma mater de nossa sociabilidade colonial, mais do que, desse ponto de vista, a relação entre a casa grande e a senzala (Freyre, 2019).

Na camada livre e sem posses, a família não se organizou para a realização das funções sociais apontadas para os estratos dominantes. A inexistência de propriedade 
econômica relevante, a impossibilidade de participação no poder político, isto é, a marginalização em face da sociedade global, excluem evidentemente essa suposição. Se os amplos sistemas de parentesco tiveram por fundamento, no Brasil, a manutenção do poder, não há sequer plausibilidade em presumir a existência de formações análogas nos grupos socialmente dominados. Não obstante, a organização familiar nessas camadas inferiores inclui vários caracteres do tipo patriarcal, transferidos do modelo oferecido pelas camadas altas. (Franco, 1997, p. 45)

Eis aí uma definição plausível, avançada por José de Souza Martins em entrevista à Pesquisa FAPESP, para o que Florestan havia identificado como situação de "anomia" dos indivíduos, famílias e coletividades negras, entendida aqui pela metáfora durkheimiana sobre as situações em "que as pessoas estão vivendo socialmente, mas não sabem bem como estão vivendo, não conhecem as normas e os valores da sociedade que se desenvolve" (de Oliveira \& Moura, 2008, p. 10). Ainda que, no caso de Franco, a referência seja feita em relação às famílias dos "homens pobres livres" do período escravocrata, mas que também, de alguma forma, pode ser utilizada para a compreensão do conjunto das famílias pobres (pretas, brancas ou mestiças) do período pós-abolição, que neste ensaio defino como "homens comuns" brasileiros.

Mas o que nos interessa, neste momento, é compreender o efeito dessa obnubilação da autoconsciência na vida dos homens pobres livres que viviam sob uma efetiva "dominação pessoal" durante o regime escravocrata, o foco de investigação da socióloga paulista.

Plenamente desenvolvida, a dominação pessoal transforma aquele que a sofre numa criatura domesticada: proteção e benevolência lhe são concedidas em troca de fidelidade e serviços reflexos. Assim, para aquele que está preso ao poder pessoal se define um destino imóvel, que se fecha insensivelmente no conformismo. (Franco, 1997, p. 95)

E dessa situação de indigência social - no sentido de seu "caráter prescindível" (diferente da situação do cativo) na estrutura socioeconômica daquele período histórico, o que lhe propiciou uma concepção de si como "imutável e fechada", "na medida em que as suas necessidades mais elementares dependeram sempre das dádivas de superiores" (Franco, 1997, p. 111) - é que os diversos tipos desse "homem comum" brasileiro em formação (tropeiros, vendeiros, sitiantes, agregados ou camaradas) acabaram por se revelar, na média, em sujeitos sem vontade, com grandes dificuldades de tomar decisões autônomas. Quando muito, apenas de forma episódica, em movimentos messiânicos, "abriu-se para ele a possibilidade de desvendar o mundo do ponto de vista das mudanças que nele pretendia realizar" (Franco, 1997, p. 112-113). Messiânicos, mas não necessariamente "regressivos". 
Expressam, antes, "a organização transitória da população rural justamente com base no modelo oferecido pela 'civilização' que sempre existiu paralelamente a ela" (Franco, 1997, p. 112-113).

De toda forma, ainda que com correspondência às necessidades imediatas de existência, baseados numa racionalidade que continha elementos de cálculos que se aproximavam de uma weberiana "atuação racional com relação a fins", estes movimentos foram incipientes para colaborar na organização de um futuro coletivo que canalizasse positivamente "as energias do caipira" contra um mundo que lhe era bastante desfavorável.

Por tudo isso, a visão crítica da sociedade em que ele não tinha razão de ser - embora estivesse dada como possibilidade - perdeu-se na impossibilidade de querer socialmente alguma coisa. Em tais condições, o caminho do homem pobre foi, o mais das vezes, o de reafirmar sua submissão. Sua inexistência como ser social permitiu uma única escapatória nos momentos em que as forças constritivas se faziam sentir mais duramente: a revolta de cada indivíduo, solitário em seu desafio à ordem estabelecida, entregue às suas próprias forças para afirmar-se. (Franco, 1997, p. 113)

Existiram tentativas de mudança. Mas este "sujeito de um mundo tosco", infernal, materialmente pobre, não ia além do imediato vivido, e a transcendência possível se esgotou nos predicados de sua capacidade de organização agressiva, fazendo com que a coragem, em formas violentas, reaparecesse como significado pleno, mas fútil, da vida caipira. Para piorar, essa herança da pobreza foi, paulatinamente, usurpada pela administração pública que iria enriquecer, senão o patrimônio estatal, as autoridades oficiais que utilizavam a influência pessoal para benefício próprio.

Essa mistura entre a coisa pública e os negócios privados fundamenta, sem dúvida a extensão do controle pessoal a todo o patrimônio do Estado. A passagem é rápida: o homem que sustenta com recursos particulares as realizações próprias do governo está subjetivamente pronto para considerar como seu o conjunto de bens públicos confiados à sua guarda. (Franco, 1997, p. 131)

Quem não o faria? Parece perguntar a autora, para responder logo em seguida:

Transformar a autoridade inerente ao cargo em instrumento usado diretamente em proveito próprio é tão da ordem das coisas quanto servir-se da superioridade garantida pela riqueza, pela posição na sociedade ou na política, para pressionar o agente governamental. (Franco, 1997, p. 137)

Como se percebe, a construção do futuro estava presa as peias do passado, tanto no que se refere à sociabilidade do homem comum brasileiro em gestação, quanto às 
relações políticas que ensejaram a constituição do chamado "Estado nacional" tupiniquim, no período que vai da ascensão até o início da queda dos barões da cafeicultura.

Assim sendo, embora impostos de fora os novos modelos de organização administrativa e embora tomadas as providências para garanti-los praticamente, criando estímulos e controles da atuação de seus funcionários, não se logrou produzir uma "moralidade" correspondente. Não estavam dadas as condições para isso, não se completando a separação entre pessoal administrativo e meios materiais da Administração. As coisas públicas continuaram a ser usadas diretamente pelo grupo no poder e de acordo com o tipo de relações básicas na organização social: a dominação pessoal. (Franco, 1997, p. 140)

Não cabe pormenores sobre os negócios que misturaram "padrões costumeiros" e "práticas capitalistas" que, articulados, acabaram por engendrar uma "especialização bastante rudimentar de exploração" econômica e social, baseada na intensificação da divisão do trabalho social do setor cafeeiro. E que teve como resultado um lento processo de diversificação, até hoje ainda não tão ampliado e desenvolvido, de produção das nossas riquezas nacionais. Vale apenas ressaltar que a derrocada dos fazendeiros da "civilização" do café - que teve como motivação não, necessariamente, o "apego irracional" de sua mentalidade ao rotineiro e ao tradicional, mas justamente, à sua "esperança irracional" nas inovações - não deu lugar há algo muito diferente das suas "unidades mercantis de produção" (Franco, 1997, p. 196). Isto significa dizer, que apesar da substituição do trabalho servil pelo trabalho supostamente assalariado, "o patrão de homens livres desempenhou funções análogas" ao regime anterior, salvo apenas um período de "compromisso fugaz entre a práxis do fazendeiro", que tinha de enfrentar o problema de suprimento de mão-de-obra, "e o projeto do imigrante, que também se sujeitou às condições adversas iniciais, a fim de superar a condição que rejeitara ao abandonar seu país de origem e realizar sua independência" (Franco, 1997, p. 201).

Depois, progressivamente, a grande fazenda de café foi regularizada, novamente organizando-se sobre a base de trabalhadores expropriados, com remuneração mais ou menos no nível de subsistência, congregados em atividades centralizadas sob o controle do fazendeiro. (Franco, 1997, p. 201)

Este tipo de "empresa econômica", baseado num modelo de fazenda na qual o proprietário mantém sob o seu poder todos os meios de produção e trabalho, "diferencia-se radicalmente da forma de exploração capitalista da terra" (Franco, 1997, p. 201). Este sistema, bastante emperrado, devido ao quase nulo estoque de capitais 
que produzia, sempre a mercê de intermediários (num primeiro momento ligado ao tráfico negreiro, depois ao comércio da imigração, ainda que com subsídio estatal), um "dia veio que esse estado de coisas voou pelos ares (Franco, 1997, p. 207). Isto se deu porque a organização econômica e a estrutura social brasileira se ergueram sob"um princípio rígido" de produção de monoculturas sempre dependente e condicionado pelos "mercados mundiais".

Vê-se, pois, como se definiu para os destinos dessa sociedade uma situação de extrema ambigüidade: de um lado, a própria dinâmica dos processos econômicos a que esteve vinculada impediu a estabilização de uma camada privilegiada [que se renovava, claro, mas num processo de "inapelável decadência"]; de outro, essa estrutura social era inteiramente [abalada pela] falta da plasticidade que seria requerida para a superação das crises mantendo-se a continuidade da ordem social. Para um ajustamento deste tipo, seria necessária uma abertura muito maior dos canais de ascensão sócio-econômica, correlata com uma maior diversificação da própria economia interna. (Franco, 1997, 217)

O resultado disso foi um país de baixíssimo patrimônio cultural, escassa diferenciação social, sob grande desigualdade econômica, e fraquíssima participação política - o que faz Franco (1997, p. 237) afirmar que por aqui "não se completou o processo de constituição de uma sociedade de classes". Por outro lado, não se pode presumir que nossa autora concorde com uma caracterização do Brasil marcado por uma ordem tipicamente "patrimonial", com uma respectiva camada senhorial de corte estamental que a tudo e a todos domina - tal como foi qualificada por Cardoso (1977). Na perspectiva da socióloga, o que tivemos foi uma "unidade contraditória" que respondia de modo próprio "às determinações mais gerais da expansão do capitalismo e da construção da sociedade moderna" (Botelho, 2013, p. 354).

O que salta da sociologia-histórica de Franco, afirma Botelho (2013, p. 354), é a "qualificação da historicidade da vida social", o alerta permanente de que "a interação entre tradição e modernidade constitui, por si só, um problema histórico de pesquisa, e, assim, não poderia ser substituído por qualquer dedução lógica ou ideológica". Ainda segundo Botelho, outros dois grandes méritos da socióloga foram: realizar uma análise do processo de modernização da sociedade brasileira e latino-americana alternativa às elaboradas pelas diversas tendências então hegemônicas da "sociologia do desenvolvimento"; e, por complemento, realizar uma crítica dos pressupostos teóricos dessas mesmas perspectivas, com destaque para o modo inapropriado com que categorias weberianas foram tomadas a partir de uma perspectiva funcionalista. 


\section{Considerações finais}

Em homenagem recente, Arruda (2018, p. 11) localiza a obra de José de Souza Martins no "rol dos mais fecundos e marcantes intelectuais e cientistas sociais brasileiros", devido aos "atributos revelados nos múltiplos temas, objetos, interesses e ângulos inusitados de interpretação" - uma visão sociológica construída a partir da "margem", que lhe "permitiu criar um pacto de solidariedade e de sentido com os que se situam nas franjas da vida social". Pelo que vimos até aqui, essa era, enfim, uma das mais fortes características da própria escola intelectual à qual ele esteve vinculado e que, de alguma forma, é um dos seus continuadores.

Na trilha de investigação proposta, analisando dois clássicos livros da Escola Paulista de Sociologia - A integração do negro na sociedade de classes e O homem livre na sociedade escravocrata - constatamos que as respectivas visões de Fernandes e Carvalho sobre algumas das condições "infernais" que conformaram a "sociabilidade do homem comum brasileiro", também podem ser consideradas como parte de uma ciência social "enraizada", inaugurada por Florestan, que buscou, nas palavras de Frehse (2018, p. 13), "encarar" o Brasil, a partir de São Paulo, "como um laboratório de descobertas sociológicas", rico de metodologias e de divergências epistêmicas dialógicas. Se como diz Martins, em entrevista recente, "os clássicos devem ser relidos sempre" (Fachin, 2019), os que aqui selecionamos, como esperamos ter demonstrado, trazem subsídios relevantes para nos fazer refletir sobre as articuladas relações sociais pedagógicas - racistas, violentas e, respectivamente, exploradoras - que ainda há entre indivíduo e sociedade nas nadas "edênicas" terras brasileiras. Quem sabe assim encontremos caminhos que nos faça realizar uma terceira e profunda abolição, nos redimindo de todas as anteriores que ficaram no meio da travessia.

\section{Notas}

Por decisão pessoal, o autor do texto escreve segundo o novo acordo ortográfico.

\section{Referências}

Arruda, M. A. (1994). A trajetória da pesquisa na Sociologia. Estudos Avançados, 8(22), 315-324.

https:/ / www.scielo.br/scielo.php?script=sci_arttext\&pid=S0103-401419940003000 $40 \& \operatorname{lng}=$ en\&nrm $=$ iso 
Arruda, M. A. (1996). Dilemas do Brasil moderno: a questão racial na obra de Florestan Fernandes. In M. C. Maio \& R. V. Santos (Orgs.), Raça, ciência e sociedade (pp. 195-203). FIOCRUZ/CCBB.

Arruda, M. A. (2018). Uma sociologia da Margem. In F. Frehse (Org.), A sociologia enraizada de José de Souza Martins (pp. 9-12). Com-Arte.

Bastos, É. R. (1987). A questão racial e a revolução burguesa. In M. A. D’Incao (Org.), O saber militante: ensaios sobre Florestan Fernandes (pp. 140-150). Paz e Terra, UNESP.

Botelho, A. (2013). Teoria e história na sociologia brasileira: a crítica de Maria Sylvia de Carvalho Franco. Lua Nova, (90), 331-366.

https:/ / www.scielo.br/scielo.php?script=sci_arttext\&pid=S0102-644520130003000 $12 \& \operatorname{lng}=$ en\&nrm $=$ iso

Campos, A. J. M. (2014). Interfaces entre sociologia e processo social: a integração do negro na sociedade de classes e a pesquisa Unesco em São Paulo (Dissertação de Mestrado). Universidade Estadual de Campinas.

Candido, A. (2010). Os parceiros do Rio Bonito. (11 a ed.). Edusp.

Cardoso, F. H. (1977). Capitalismo e escravidão no Brasil meridional: o negro na sociedade escravocrata do Rio Grande do Sul ( $2^{\mathrm{a}}$ ed.). Paz e Terra.

Carvalho, J. M. (1998). O motivo edênico no imaginário social brasileiro. Revista Brasileira de Ciências Sociais, 13(38), 63-79.

https://www.scielo.br/scielo.php?script=sci_arttext\&pid=S0102-690919980003000 $04 \& \operatorname{lng}=$ en\&nrm=iso

Cohn, G. (2000). Florestan Fernandes: A Integração do Negro na Sociedade de Classes. In L. D. Mota (Org.), Introdução ao Brasil: um banquete nos trópicos (Vol. 2, pp. 387-402). Senac.

de Oliveira, M., \& Moura, M. (2008, maio). José de Souza Martins: A sociologia que examina as margens, os sonhos e a esperança. Pesquisa FAPESP, 147, pp. 8-15.

Fachin, P. (2019, 09 de setembro). Os sociólogos distraídos e a invasão ideológica nas Ciências Sociais. Entrevista especial com José de Souza Martins. Revista IHU-On line. http://www.ihu.unisinos.br/159-noticias/entrevistas/592388-ossociologos-distraid os-e-a-invasao-ideologica-nas-ciencias-sociais-entrevista-especialcom-jose-de-souzamartins

Fernandes, F. (1975). A revolução burguesa no Brasil: ensaio de interpretação sociológica. Zahar Editores.

Fernandes, F. (2003). O folclore em questão ( $2^{\mathrm{a}}$ ed.). Martins Fontes.

Fernandes, F. (2008a). A integração do negro na sociedade de classes: o legado da "raça branca" (5 ed., Vol. 1). Globo.

Fernandes, F. (2008b). A integração do negro na sociedade de classes: no limiar de uma nova era (Vol. 2). Globo.

Fernandes, F., \& Bastide, R. (1971). Brancos e negros em São Paulo: ensaio sociológico sobre aspectos da formação, manifestações atuais e efeitos do preconceito de cor na sociedade paulistana ( $3^{\mathrm{a}}$ ed.) Companhia Editora Nacional. 
Franco, M. S. C. (1997). Homens livres na ordem escravocrata (4 $4^{a}$ ed.). Fundação Editora Unesp.

Franco, M. S. C. (2011). Entrevista com Maria Sylvia de Carvalho Franco.

Trans/Form/Ação, 34(especial), 167-177.

https:/ / www.scielo.br/scielo.php?script=sci_arttext\&pid=S0101-317320110003000 $07 \& \operatorname{lng}=$ en\&nrm $=$ iso

Frehse, F. (2018). Uma "festchrift" sociológica enraizada. In Frehse, F. (Org.), A sociologia enraizada de José de Souza Martins (pp. 13-18). Com-Arte.

Freyre, G. (2019). Casa grande e senzala: formação da família brasileira sob o regime da economia patriarcal. Global.

Holanda, S. B. (2000). Visão do paraíso: os motivos edêmicos no descobrimento e colonização do Brasil. Brasiliense e Publifolha.

Ianni, O. (2004). Raça e classes sociais no Brasil. Brasiliense.

Kowarick, L. (2019). Trabalho e vadiagem: a origem do trabalho livre no Brasil. Editora 34.

Lépine, C. (1987). A imagem do negro brasileiro. In M. A. D’Incao (Org.), O saber militante: ensaios sobre Florestan Fernandes (pp. 129-139). Paz e Terra, UNESP.

Maio, M. C. (1997). A história do Projeto Unesco: estudos raciais e ciências sociais no Brasil (Tese de Doutoramento). Instituto Universitário de Pesquisas do Rio de Janeiro -IUPERJ.

Martins, H. H. T. de S. (2004). Metodologia qualitativa de pesquisa. Educação e Pesquisa, 30(2) 289-300.

Martins, J. S. (1998). Florestan: sociologia e consciência social no Brasil. EDUSP.

Martins, J. S. (2018). Moleque de fábrica: uma arqueologia da memória social. Ateliê Editorial.

Monsma, K. M. (2016). A reprodução do racismo: fazendeiros, negros e imigrantes no oeste paulista, 1880-1914. EdUFSCar.

Nogueira, O. (2006). Preconceito racial de marca e preconceito racial de origem: sugestão de um quadro de referência para a interpretação do material sobre relações raciais no Brasil. Tempo Social - Revista de Sociologia da USP, 19(1), 287-308.

Piozzi, P. (1997). Orelha do livro. In M. S. C. Franco, Homens livres na ordem escravocrata ( $4^{\mathrm{a}}$ ed.). Fundação Editora Unesp.

Pulici, C. (2008). Entre sociólogos: versões conflitivas da "condição de sociólogo" na USP dos anos 1950-1960. Edusp/Fapesp.

Soares, E. V., Braga, M. L. S., \& Costa, D. V. A. (2002). O dilema racial brasileiro: de Roger Bastide a Florestan Fernandes ou da explicação teórica à proposição política. Sociedade e Cultura, 5(1), 35-52.

Spirandelli, C. C. (2008). Trajetórias intelectuais: professoras do Curso de Ciências Sociais da FFCL-USP (1934-1969) (Tese de Doutoramento). Universidade de São Paulo.

Data de submissão: 14/06/2020 | Data de aceitação: 26/05/2021 